\section{THU0097 CHANGE IN SELF-REPORTED PAIN REFLECTS PSYCHOLOGICAL AND FUNCTIONAL STATE RATHER THAN INFLAMMATORY BURDEN IN UNITED STATES LATINOS WITH ESTABLISHED RHEUMATOID ARTHRITIS}

G. Karpouzas, E. Hernandez, C. Cost, S. Ormseth. Rheumatology, Harbor-UCLA Medical Center, Torrance, United States

Background: Pain represents the cardinal complaint in patients with rheumatoid arthritis (RA). It may reflect inflammation, structural damage, or aberrant processing and regulatory mechanisms.

Objectives: We evaluated whether changes in pain reflect inflammatory burden variation or non-inflammatory factors in Latinos with established RA in the United States (US).

Methods: We evaluated 271 patients from a single academic center with complete data in parameters of interest on 2 visits, 12 months apart. Demographics, serologies, swollen and tender joint assessments, sedimentation rate, fatigue-VAS (visual analogue scale), pain-VAS, depression assessment (Patient Health Questionnaire-PHQ9), functional disability (Health Assessment Questionnaire, HAQ-DI), presence of erosions and irreversible articular damage (IAD, including subluxation, fusion, arthrodesis, or prosthesis) were recorded. Principal components factor analysis with varimax rotation determined latent variables of symptom change. Multinomial logistic regression modeling with forward stepwise entry determined parameters associated with clinically meaningful change in pain compared to no change

Results: Two factors met acceptance criteria (Eigenvalues $\geq 1$ ) with values of 2.57 and 1.31 respectively (Table 1). Following rotation, factor 1 loadings comprised change in fatigue, pain, depression scores, and functional disability, representing non-inflammatory factors. Conversely, factor 2 encompassed changes in tender and swollen joints and ESR, representing inflammation. Clinically relevant improvement in pain significantly correlated with respective improvements in fatigue, depression, functional disability and tender joints (Table 2); worsening pain was negatively associated with change in disability or fatigue.

Table 1: Principal Component factor analysis with change variable loadings
\begin{tabular}{|l|l|l|}
\hline & Factor $1^{\star}$ & Factor $2^{\star}$ \\
\hline Fatigue change & 0.814 & -0.019 \\
\hline Pain change & 0.757 & 0.216 \\
\hline PHQ9 change & 0.716 & 0.024 \\
\hline HAQ-DI change & 0.569 & 0.328 \\
\hline Swollen joint count change & 0.095 & 0.828 \\
\hline Tender joint count change & 0.238 & 0.696 \\
\hline Sedimentation Rate change & 0.003 & 0.642 \\
\hline${ }^{*}$ Factor 1 explains 30.6\% of variance and factor 2 explains 24.8\% \\
\hline
\end{tabular}

Table 2: Factors associated with clinically meaningful change in self-reported pain

Table 2: Factors associated with clinically meaningful change in self-reported pain
\begin{tabular}{|l|l|l|l|l|l|l}
\hline & parameters & B & Std Error & p-value & OR & $\mathbf{9 5} \% \mathrm{Cl}$ \\
\hline \multirow{5}{*}{ Worsening } & Intercept & -1.437 & 0.213 & 0.000 & & \\
\cline { 2 - 7 } & PHQ9 change & -0.011 & 0.034 & 0.752 & 0.989 & $0.925-1.058$ \\
\cline { 2 - 7 } & TJC change & -0.026 & 0.025 & 0.314 & 0.975 & $0.927-1.025$ \\
\cline { 2 - 7 } & HAQ-DI change & -1.254 & 0.358 & 0.000 & 0.285 & $0.142-0.575$ \\
\cline { 2 - 7 } & Fatigue change & -0.223 & 0.073 & 0.002 & 0.800 & $0.693-0.923$ \\
\hline \multirow{5}{*}{ Improving } & Intercept & -1.186 & 0.192 & 0.000 & & \\
\cline { 2 - 7 } & PHQ9 change & 0.088 & 0.035 & 0.012 & 1.092 & $1.020-1.169$ \\
\cline { 2 - 7 } & TJC change & 0.066 & 0.028 & 0.016 & 1.069 & $1.012-1.128$ \\
\cline { 2 - 7 } & HAQ-DI change & 0.627 & 0.317 & 0.048 & 1.871 & $1.005-3.483$ \\
\cline { 2 - 7 } & Fatigue change & 0.204 & 0.067 & 0.002 & 1.226 & $1.075-1.339$ \\
\hline
\end{tabular}
Reference category is no change

Conclusions: In Latinos with established RA, change in pain reporting reflects alterations in non-inflammatory parameters such as fatigue, depression and functional disability rather than inflammation. Active screening and consideration of those factors may inform therapeutic interventions, balance patient and physician expectations, and optimize patient satisfaction and clinical outcomes. Disclosure of Interest: None declared

DOI: 10.1136/annrheumdis-2017-eular.6813

\section{THU0098 THE NAILFOLD CAPILLAROSCOPY IN RHEUMATOID ARTHRITIS: QUANTITATIVE ANALYSIS AND CLINICAL AND SEROLOGICAL CORRELATION}

G. Cuomo, E. Frongillo, L. Pirro, A. Del Mastro, C. Romano. Dipartimento Assistenziale Integrato di Medicina Interna, UOC Medicina Interna - Università degli Studi della Campania - Luigi Vanvitelli, Napoli, Italy

Background: Nailfold videocapillaroscopy (NVC) abnormalities have been reported in patients with Rheumatoid Arthritis (RA). Nevertheless only few studies evaluated the grades of the detected alterations $(1,2)$. In 1994, Hachulla et al., showed microvascular permeability alterations in RA, to confirming the existence of a microangiopathy (3). In addition, Meyer et al. showed modifications of the normal blood flow velocity and microvascular dysfunction in RA (4).

Objectives: The aim of this study was to evaluate, in RA patients and healthy controls $(\mathrm{HC})$, the microcirculatory abnormalities through NVC, applying a qualitative and quantitative method. We also correlated abnormalities with clinical and immunological features

Methods: Thirty-five $\mathrm{HC}$ ( 35 females, 7 males, median age 55, range $32-70$ ) and 70 RA patients (61 females, median age 58 years, range $30-75$; median disease duration 12 years, range $1-20$ ) consecutively admitted to our outpatient clinic, were examined. All patients underwent a full clinical-serological characterization. Both patients and controls underwent NVC, with optical probes of 200X (VideoCap 2.5). We excluded patients who showed conditions known to compromise microcirculation, such as diabetes, hypertension, overlap with other connective tissue diseases or certain pharmacological treatments. The following NVC parameters were evaluated with a semiquantitative method: capillary enlargement (ectasias), microhemorrhages, mean capillary density, capillary tortuosity (5).

Results: NVC alterations were detected in 55 of $70(68.6 \%)$ RA patients: 40 $(57 \%)$ patient showed ectasic capillaries; $21(30 \%)$ decrease of the mean capillary density; $12(17 \%)$ microhemorrhages; 46 (65.7\%) capillary tortuosity. No patient had megacapillaries and/or neoangiogenic abnormalities.

A statistically significant difference between $\mathrm{HC}$ and RA patients was found for the detection of ectasias $(p<0,0001)$ and for the decrease of the mean capillary density $(p<0,001)$.

No differences emerged in RA patients between NVC pattern and/or immunological (ANA, ACPA, Rheumatoid Factor) and/or serological profile (ESR, CRP, lipid profile).

Nevertheless we found a correlation between NVC abnormalities (microhrmorrhages) and activity disease evaluated by DAS28 $(p=0.0037)$

Conclusions: Our study confirms the presence of a sub-clinical microvascular involvement in RA patients either with or without microvascular clinical manifestations.

In our opinion capillaroscopy can be considered a valid technique in inflammatory joint diseases to analyze microvascular circulation. Moreover, the correlation of NVC specific alteration with disease activity suggests the importance of these features in the assessment of RA patients.

\section{References:}

[1] Granier F, et al. Arthristi Rheum 1996.

[2] Nagy and Czirjiak. J Eur Acad Derm Venerol 2004.

[3] Hachulla et al, J Rheumatol 1994.

[4] Meyer. Rheumato Int 2007.

[5] Ingegnoli et al,Seminar Arthitis Rheum 2009

Disclosure of Interest: None declared

DOI: 10.1136/annrheumdis-2017-eular.6829

\section{THU0099 THE 2010 CLASSIFICATION CRITERIA AND A MORE AGGRESSIVE TREATMENT STRATEGY IMPROVE CLINICAL OUTCOMES IN SEROPOSITIVE BUT NOT SERONEGATIVE RHEUMATOID ARTHRITIS}

G. Crepaldi, S. Bugatti, F. Benaglio, G. Sakellariou, A. Manzo, C. Montecucco, R. Caporali. Department of Rheumatology, IRCCS Policlinico San Matteo Foundation, Pavia, Italy

Background: Current guidelines recommend an early and intensive treatment in patients diagnosed with rheumatoid arthritis (RA), and the 2010 ACR/EULAR Classification Criteria were developed with the aim of allowing earlier diagnosis and treatment $(1,2)$. Recent studies highlighted some differences in disease activity between seropositive and seronegative RA patients at disease onset (3). Objectives: To investigate whether the application of the 2010 ACR/EULAR Classification Criteria and a more aggressive treatment strategy improve clinical outcomes in patients with early RA irrespective of the autoantibody status.

Methods: 584 early, treatment-naïve RA patients were recruited in the years 2005-2014. RA diagnosis was made according to the ACR 1987 criteria in 20052010 ( $n=360$, cohort 1987), and to the 2010 ACR/EULAR criteria in 2011-2014 $(n=224$, cohort 2010). Patients were classified in autoantibody (Ab)-negative (negative rheumatoid factor (RF) and/or anticitrullinated peptide antibody (ACPA) and Ab-positive (RF and/or ACPA positive). Methotrexate (MTX) was used at the initial dosage of $10 \mathrm{mg} /$ week in cohort 1987, and $15 \mathrm{mg} /$ week in cohort 2010, and progressively increased if low disease activity (LDA) (DAS28 $\leq 3.2$ ) was not met. The frequency and predictors of LDA and clinical remission (DAS28<2.6) over 6 months were assessed by Cox regression.

Results: In Ab-negative patients, LDA and clinical remission were achieved in $62.8 \%$ and $37.2 \%$ of the cases, and the 2010 cohort did not show significantly improved outcomes (HR [95\% Cl] 0.86 [0.611.23] for LDA; 1.04 [0.651.69] for remission) (Figure $1 \mathrm{~A}, \mathrm{~B})$. In contrast, in Ab-positive patients, the application of the 2010 classification criteria and higher dosages of MTX were associated with increased frequency of LDA after adjustment for confounders (age, sex, prednisone, baseline DAS28; HR [95\% Cl] 1.39 [1.012]) (Figure 1C). Clinical remission was achieved in $41.3 \%$ of the cases, compared to $29.6 \%$ in the 1987 cohort $(p=0.17)$ (Figure 1D)

Conclusions: Early diagnosis and a more aggressive treatment strategy with MTX lead to significantly improved outcomes in autoantibody positive RA. The management of seronegative patients remains suboptimal.

References:

[1] Smolen JS et al. Treating rheumatoid arthritis to target: 2014 update of the recommendations of an international task force. Ann Rheum Dis 2016.

[2] Aletaha D et al. 2010 rheumatoid arthritis classification criteria: an ACR/EULAR collaborative initiative. Ann Rheum Dis 2010.

[3] Nordberg LB et al. Patients with seronegative RA have more inflammatory activity compared with patients with seropositive RA in an inception cohort of DMARD naive patients classified according to 2010 ACR/EULAR criteria. Ann Rheum Dis 2017. 

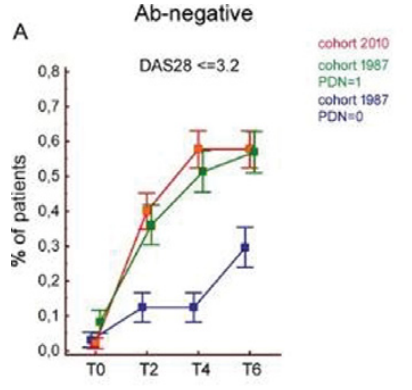

B

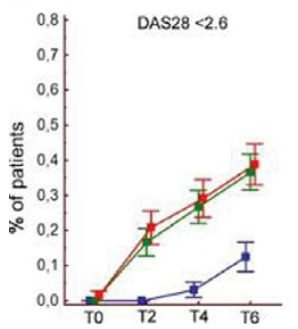

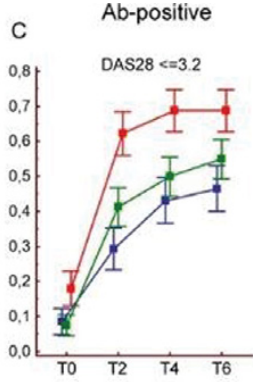

D

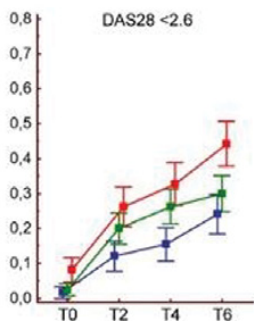

Disclosure of Interest: None declared

DOI: 10.1136/annrheumdis-2017-eular.5101

\section{THU0100 IN EARLY INFLAMMATORY ARTHRITIS A LYMPHOID PATHOTYPE SIGNFICANTLY ASSOCIATES WITH REQUIREMENT FOR BIOLOGIC THERAPY AT 12 MONTHS FOLLOW UP: RESULTS FROM THE PATHOBIOLOGY OF EARLY ARTHRITIS COHORT (PEAC)}

G. Lliso-Ribera ${ }^{1}$, F. Humby ${ }^{1}$, S. Kelly ${ }^{1}$, M. Bombardieri ${ }^{1}$, M. Lewis ${ }^{1}$, R. Hands ${ }^{1}$, V. Rocher ${ }^{1}$, F. Bene ${ }^{1}$, A. Nerviani ${ }^{1}$, C. Buckely ${ }^{2}$, P. Taylor ${ }^{3}$, I. McInnes ${ }^{4}$,

C. Pitzalis ${ }^{1}{ }^{1}$ Experimental Medicine and Rheumatology, Queen Mary University London, London; ${ }^{2}$ Centre for Translational Inflammation Research, University of Birmingham, Birmingham: ${ }^{3}$ Kennedy Institute of Rheumatology, University of Oxford, Oxford; ${ }^{4}$ Experimental Medicine and Rheumatology, University of Glasgow, Glasgow, United Kingdom

Background: Early aggressive treatment in RA equates to better long term outcomes, however targeting aggressive therapies including biologics to patients with the worse prognosis is critical to deliver acceptable risk/benefit ratios and health economic improvements. Such an approach requires prognostic biomarkers, whether the well recognised heterogeneity in synovial pathobiology in early RA translates to specific disease outcomes is currently unknown.

Objectives: The aim of this study was to investigate whether in a treatment naïve early inflammatory arthritis cohort, baseline synovial pathotype significantly associates with disease outcome at 12 months.

Methods: 166 consecutive DMARD naïve patients recruited as part of PEAC at Barts Health NHS Trust with synovial tissue suitable for analysis were included. At baseline patients were classified as RA (2010 ACR/EULAR criteria) or undifferentiated (UA). All patients underwent a baseline synovial biopsy of a clinically active joint along with collection of demographic data. Patients were subsequently treated with DMARD +/- steroid therapy with aim for low disease activity (DAS <3.3). At 6 month follow up patients were escalated to biologic therapy if fulfilling UK NICE guidelines. At 12 months patients were classified as: (i) no treatment, (ii) DMARDs, and (iii) Biologic +/- DMARDs. Sequentially cut sections of baseline synovial biopsies underwent immunohistochemical staining and semi-quantitative scoring (0-4) to determine the degree of CD20+Bcells, CD3+T cells, CD68+ lining (I) and sublining (sl) macrophage and CD138+ plasma cell infiltration. Sections were categorised into 3 pathotypes, (i) Fibroid: (CD68 $\mathrm{SL}<2$ and or CD3, CD20, CD138<1), (ii) Myeloid: (CD68SL $>2, C D 20<1$ and or CD3 $>1$ ) and (iii) Lymphoid: (grade 2-3 CD20+ aggregates, CD20>2).

Results: $79 \%$ were classified as RA and $21 \%$ as UA. Mean disease duration was 9.27 months. 92\% (153/166) patients had follow-up at 12 months. $29 \%(44 / 153)$ of patients were classified as fibroid, $34 \%(52 / 166)$ as myeloid and $37 \%(57 / 166)$ as lymphoid. At baseline patients with a lymphoid pathotype had a significantly higher CRP and DAS28 and were significantly more likely to be sero positive for for RF and ACPA $(p<0.05)$, suggesting that a lymphoid pathotype is associated with higher levels of disease activity. At 12 months follow up a significantly higher proportion of patients classified as lymphoid vs myeloid or fibroid (58\% vs $21 \%$ vs $21 \%$ ) required biologic therapy.

Conclusions: Results demonstrate that in an early inflammatory arthritis cohort

\begin{tabular}{lcccr}
\hline N=153 & Fibroid (44) & Myeloid (52) & Lymphoid (57) & p-value \\
\hline No treatment (14) n (\%) & $6(42 \%)$ & $6(42 \%)$ & $2(14 \%)$ & $<0.05^{*}$ \\
DMARD (101) n (\%) & $30(29 \%)$ & $38(37 \%)$ & $33(32 \%)$ & \\
Biologic +/- DMARD (38) n (\%) & $8(21 \%)$ & $8(21 \%)$ & $22(58 \%)$ & \\
\hline
\end{tabular}

a lymphoid pathotype significantly associates with higher disease activity at baseline, sero positivity for RF and ACPA and a requirement for more aggressive therapy at 12 month. This supports a direct role for synovial lymphoid structures in disease pathogenesis and suggests a role as a prognostic biomarker facilitating early stratification of aggressive therapeutic intervention

Disclosure of Interest: None declared

DOI: 10.1136/annrheumdis-2017-eular.6042

\section{THU0101 CARDIOVASCULAR MAGNETIC RESONANCE IMAGING CHARACTERISATION OF CARDIOVASCULAR ABNORMALITIES IN INDIVIDUALS AT RISK OF DEVELOPING RHEUMATOID ARTHRITIS}

G.J. Fent ${ }^{1}$, L. Hunt ${ }^{2,3}$, K.S. Mankia ${ }^{4,5}$, B. Erhayiem ${ }^{1}$, J.R. Foley ${ }^{1}$, P. Garg ${ }^{1}$, P.P. Swoboda ${ }^{1}$, J. Andrews ${ }^{4,5}$, J.P. Greenwood ${ }^{1}$, P. Emery ${ }^{4,5}$, S. Plein ${ }^{1}$, M.H. Buch ${ }^{1,5}{ }^{1}$ Leeds Institute of Cardiovascular and Metabolic Medicine, University of Leeds, UK; ${ }^{2}$ NIHR Leeds Musculoskeletal Medicine, University of Leeds, United Kingdom; ${ }^{3}$ Leeds Institute of Rheumatic and Musculoskeletal Medicine, University of Leeds, United Kingdom; ${ }^{4}$ Leeds Institute of Rheumatic and Musculoskeletal Medicine; ${ }^{5} \mathrm{NIHR}$ Leeds Musculoskeletal Medicine, University of Leeds, Leeds, United Kingdom

Background: Inflammation is the primary contributor to excess cardiovascular (CV) disease in rheumatoid arthritis (RA), with evidence of subclinical abnormalities observed even in treatment-naïve, early RA [1]. Preliminary reports suggest citrullinated proteins are present in atherosclerotic plaque [2]. It is unclear whether immunological changes of anti-citrullinated protein antibody (anti-CCP+) positive individuals "at risk" of developing RA are associated with CV abnormality. Objectives: To perform a pilot study to explore whether subclinical CV abnormalities are present in anti-CCP+ individuals at risk of developing RA.

Methods: Sixteen consecutive patients with non specific MSK symptoms but no synovitis, detectable anti-CCP antibody and 30 age-matched healthy controls (HC) underwent a multi-parametric 3.0T (Philips Achieva) cardiovascular magnetic resonance (CMR) study. Neither group had any history of CV disease. At-risk individuals were categorised as low and high absolute risk for RA development $(<50 \%$ and $\geq 50 \%$ respectively) according to a published risk model [3]. CMR post-processing was performed using CVI ${ }^{42}$ (Circle Cardiovascular Imaging, Canada).

Results: $\mathrm{HC}$ and at risk individuals were well matched for baseline characteristics (table 1). Aortic strain values (distensibility, strain and stiffness index $\beta$ ) were lower, indicating increased aortic stiffness, in at-risk individuals than $\mathrm{HC}$, numerically most pronounced those classified high risk (table 2). There were no differences in LV mass and function, late gadolinium enhancement, myocardial T1 (measure of myocardial composition) or LV S prime (Iongitudinal LV systolic function) (table 2).

Table 1. Baseine choracteristics

\begin{tabular}{|c|c|c|c|}
\hline & $\begin{array}{l}\text { All 'at risk' RA } \\
\text { potients } \\
(n=16)\end{array}$ & $\begin{array}{l}\text { Healtivy con } \\
\text { trols } \\
(n-30)\end{array}$ & D value \\
\hline Age (years) & $53=11$ & $50 \div 15$ & 0.59 \\
\hline Males & $4 / 16(25 \%)$ & $10 / 30(33 \%)$ & 0.57 \\
\hline Systolic BP (mmigig) & $121: 17$ & $120=13$ & 0.82 \\
\hline Disstolic BP (mentig) & $64 \div 11$ & $64: 11$ & 0.81 \\
\hline$B \mathrm{M}\left(\mathrm{kg} / \mathrm{m}^{2}\right)$ & $28 \div 5$ & $27 \pm 6$ & 0.47 \\
\hline Dabetes & $2 / 16$ & $0 / 30$ & 0.05 \\
\hline Active smoker & $1 / 16(6 \mathrm{~N})$ & $3 / 30(10 \mathrm{~N})$ & 0.68 \\
\hline Ex-smoker & $11 / 16(69 \%)$ & $5 / 30(17 \%)$ & 0.001 \\
\hline Mean absolute pre- & $45 \mathrm{~N}$ & - & - \\
\hline
\end{tabular}

Table 2. Results able

\begin{tabular}{|c|c|c|c|c|c|}
\hline & $\begin{array}{l}\text { All 'at risk' RA } \\
\text { individuals } \\
(0=16)\end{array}$ & $\begin{array}{l}\text { LOW 'at risk' RA } \\
\text { individuals } \\
(n=10)\end{array}$ & \begin{tabular}{|l|} 
High 'at risK' RA \\
individuals \\
(n=6)
\end{tabular} & $\begin{array}{l}\text { Hesilthy } \\
\text { controls } \\
(n=30)\end{array}$ & p value \\
\hline $\begin{array}{l}\text { Aortic Distersibility } \\
\left(10^{-1} \mathrm{mmHg}\right)\end{array}$ & $3.6 \pm 1.4$ & $4.1 \pm 1.5$ & $2.8 \pm 0.5$ & $4.7=2.0$ & 0.05 \\
\hline Aortic strain & $0.20 \div 0.06$ & $0.21: 0.07$ & $0.18 \div 0.03$ & $0.25=0.09$ & 0.03 \\
\hline $\begin{array}{l}\text { Aortic stitfness index. } \\
\text { s. }\end{array}$ & $3.5 \pm 1.0$ & $3.2 \pm 1.0$ & $4,050.8$ & $2.7 \pm 0.8$ & 0.007 \\
\hline Mvocardial native $\mathrm{T1}$ & $1215 \div 35$ & $1213 \div 36$ & $2218 \div 37$ & $1202 \div 36$ & 0.25 \\
\hline $\begin{array}{l}\text { Late Gadolinium en- } \\
\text { hancement }\end{array}$ & $1 / 16$ & $0 / 6$ & $1 / 10$ & $1 / 30$ & 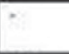 \\
\hline $\begin{array}{l}\text { IV ejection fraction } \\
\text { (s) }\end{array}$ & $62: 4$ & $62 \pm 5$ & $63: 3$ & $62 \pm 5$ & 0.94 \\
\hline $\begin{array}{l}\text { RV ejecion fraction } \\
\text { (s) }\end{array}$ & $55 \pm 6$ & 5424 & $58 \div 7$ & $54 \pm 6$ & 0.47 \\
\hline $\begin{array}{l}\text { Indexed LV mass ( } \mathrm{d} \text { ) } \\
\left.\mathrm{m}^{2}\right)\end{array}$ & $46 \div 10$ & $45 \pm 8$ & $49: 14$ & $49 \pm 8$ & 0.29 \\
\hline $\begin{array}{l}\text { Indexed tV volume } \\
\left(\mathrm{mi} / \mathrm{m}^{2}\right)\end{array}$ & $83 \div 12$ & $81 \div 13$ & $87 \pm 12$ & $80 \div 11$ & 0.34 \\
\hline tV 5 prime (s-1) & $1.1 \pm 0.1$ & $1.2 * 0.1$ & $1.0 \div 0.1$ & $1.1 \pm 0.1$ & 0.37 \\
\hline
\end{tabular}

